\title{
Medicalização no ambiente escolar
}

\author{
Medicalización en el medio ambiente escolar \\ Medicalization in the school environment
}

\author{
Ms. Maycon Hoffmann Cheffer ${ }^{1}$ \\ Dra $^{\mathrm{a}}$. Rosa Maria Rodrigues ${ }^{2}$ \\ Dra . Solange de Fátima Reis Conterno ${ }^{3}$
}

\begin{abstract}
Resumo
O cenário do ensino aprendizagem revela diferentes problemas para os quais as causas e soluções, igualmente são diversas. Dentre eles destaca-se a atribuição de soluções médicas para o seu enfrentamento. Objetivou-se problematizar as origens teóricas e históricas da medicalização no ambiente escolar. Trata-se de revisão narrativa da literatura das áreas de saúde e educação. Como resultado a medicina padronizou o comportamento dos indivíduos e para aqueles que fogem do padrão estabelecido como normal, resulta na medicalização, discurso que a escola rendeu-se disciplinarizando os indivíduos em vez de educa-los. Conclui-se que a medicalização sustenta-se na ideia de que os problemas, são oriundos de fatores internos, biológicos ou psicológicos. Ao considerar essa lógica isentam-se os variados fatores que determinam o sucesso dos escolares.
\end{abstract}

Palavras-Chave: Aprendizagem escolar; Fracasso escolar; Medicalização; Problemas de aprendizagem.

\section{Resumen}

El escenario de la enseñanza del aprendizaje revela diferentes problemas para los que las causas y las soluciones, también son diversas. Entre ellos se destaca la asignación de soluciones médicas para su enfrentamiento. Se objetivó problematizar los orígenes teóricos e históricos de la medicalización en el ambiente escolar. Se trata de una revisión narrativa de la literatura de las áreas de salud y educación. Como resultado la medicina estandarizó el comportamiento de los individuos y para aquellos que huyen del patrón establecido como normal, resulta en la medicalización, discurso que la escuela se rindió disciplinando a los individuos en vez de educarlos. Se concluye que la medicalización se sustenta en la idea de que los problemas, provienen de factores internos, biológicos o psicológicos. Al considerar esta lógica se eximen los variados factores que determinan el éxito de los escolares.

Palabras claves: Aprendizaje escolar; Fracaso escolar; Medicalización; problemas de aprendizaje.

\begin{abstract}
The learning-teaching scenario reveals different problems for which the causes and solutions are equally diverse. Among them is the attribution of medical solutions to face it. The objective was to problematize the theoretical and historical origins of medicalization in the school environment. This is a narrative review of the literature on health and education. As a result, medicine standardized the behavior of individuals and for those who flee from the standard established as normal, results in medicalization, speech that the school surrendered by disciplining individuals instead of educating them. It is concluded that medicalization is based on the idea that the problems come from internal, biological or psychological factors. In considering this logic, the various factors that determine the success of schoolchildren are exempted.
\end{abstract}

\footnotetext{
${ }^{1}$ Mestrando em biociências e saúde; Universidade Estadual do Oeste do Paraná - Unioeste; Cascavel, Paraná, Brasil; e-mail: maycon-cheffer@hotmail.com

${ }^{2}$ Doutora em educação; Universidade Estadual de Campinas - UNICAMP; Cascavel, Paraná, Brasil; e-mail: rmrodri09@gmail.com

${ }^{3}$ Doutora em educação; Universidade Federal de São Carlos - UFESCar; Cascavel, Paraná, Brasil; e-mail: solangeconterno@gmail.com
} 
Keywords: School learning; School failure; Medication; Learning problems.

\section{Introdução}

A sociedade, de forma geral, e a área da educação mais especificamente têm discutido o baixo rendimento escolar dos alunos, principalmente da escola pública, contudo, essa discussão se apresenta de maneira tímida. É possível perceber que vem ganhando espaço, no contexto escolar, um movimento que tem atribuído as causas do não aprender, das dificuldades de aprendizagem a problemas de saúde.

O processo de buscar causas físicas ou de saúde para os problemas de aprendizagem pode ser denominado como medicalização dos problemas escolares. De acordo com Collares e Moysés (1994), pode-se entender medicalização como o processo por meio do qual os problemas que fazem parte do cotidiano dos indivíduos são transformados em problemas médicos, convertendo questões de origem social e política em questões biológicas, próprias de cada indivíduo.

A medicalização no campo da educação tem gerado um fenômeno que precisa ser problematizado que é o uso exacerbado e indiscriminado de medicamentos, o qual tem reforçado a ideia de que alguns ofereceriam as condições necessárias para promover a aprendizagem. Cabe advertir que medicalização no campo da educação é um processo amplo que vai desde a indicação de medicamento (fármaco/droga) para a solução de possíveis problemas enfrentados pelos alunos no cotidiano das tarefas escolares até explicações sobre as dificuldades de aprendizagem sustentadas em conceitos e pressupostos de caráter exclusivamente biológico.

Considerando-se as questões destacadas, objetiva-se problematizar as origens teóricas do processo de medicalização e identificar nas referências da área as bases teóricas e históricas do processo de medicalização e como esse processo tem sido incorporado pela escola.

\section{Método}

Trata-se de uma revisão narrativa que tomou como fonte produções bibliográficas especializadas sobre a temática da medicalização e medicalização do espaço escolar. Segundo Cordeiro et al. (2007), a revisão de literatura narrativa ou tradicional é mais aberta ao ser comparada com a revisão sistemática, pois não exige um protocolo rígido para sua execução. 
A busca pelas referências não precisa esgotar as fontes de informações e a seleção dos estudos segue os critérios do pesquisador.

Os dados apresentados emergiram do estudo da literatura especializada das áreas de saúde e educação. O percurso metodológico adotado buscou identificar as principais referências sobre os pressupostos teóricos que embasam o processo de medicalização e como a educação ao longo do tempo incorporou a lógica desse processo para explicar as dificuldades de aprendizagem.

\section{Resultados}

\subsection{Bases teóricas e históricas da medicalização}

Torna-se importante entender como a medicina, enquanto campo de conhecimento relativo à compreensão do processo saúde-doença, da relação do homem-natureza e homemhomem, se organizou ao longo do tempo articulada a uma determinada compreensão de mundo, sociedade e homem.

A medicina, a partir dos pressupostos referentes ao que seria considerado normal, patológico, controle e disciplinarização dos comportamentos, se firmou na modernidade e divulgou seu entendimento acerca dos problemas e condições de saúde, principalmente a partir de uma lógica centrada nos aspectos biológicos, em que os problemas de saúde seriam oriundos exclusivamente de causas individuais e biológicas.

\footnotetext{
A medicina do século XIX regula-se mais, em compensação, pela normalidade do que pela saúde; é em relação a um tipo de funcionamento ou de estrutura orgânica que ela forma seus conceitos e prescreve suas intervenções; e o conhecimento fisiológico, outrora saber marginal para o médico, e puramente teórico [...] FOUCAULT, 1977, p. 39-40).
}

Para Foucault (1977) na construção do saber e atuação da medicina moderna, dois mitos emergiram juntamente com o novo papel da medicina, sendo eles o

[...] mito de uma profissão médica nacionalizada, organizada à maneira do clero e investida, ao nível da saúde e do corpo, de poderes semelhantes aos que este exercia sobre as almas; mito de um desaparecimento total da doença em uma sociedade sem distúrbios e sem paixões, restituída à sua saúde de origem (FOUCAULT, 1977, p. $35)$.

Há, com a emergência da medicina moderna, a propagação da medicalização da sociedade como uma "profissão de fé", tendo o médico como o profissional responsável por 
essa missão em apresentar "[...] de maneira positiva a medicalização rigorosa, militante e dogmática da sociedade, por uma conversão quase religiosa e a implantação de um clero da terapêutica" (FOUCAULT, 1977, p. 35).

Paul Singer, em Prevenir e curar (1978) relatou que o conceito de medicalização, de autoria de Ivan Illich, exemplifica como a medicina, ao longo do tempo ocupou espaços da vida cotidiana que não eram do seu campo, ou seja, a medicalização transformou todas as etapas da vida em "[...] objeto de cuidados médicos específicos independentemente de haver ou não sintomas" (SINGER, 1978, p. 62).

A ideia difundida pelo raciocínio medicalizador reforça que o bem estar mental ou físico pode ser atingido no campo individual, desde que "[...] cada aspecto da vida seja cientificamente regulado [...]” (SINGER, 1978, p. 63). O processo de medicalização dos problemas ampara-se na lógica da normatização da vida, em que tudo o que não se enquadra em regras e normas sociais preestabelecidas é transformado em uma patologia. Portanto, a definição do que seja normal ou patológico não é uma questão simples, pois está permeada por ideologia que reforça um tipo de organização social.

Novos padrões de normalidade foram introduzidos a partir da segunda metade do século XIX, na área da medicina geral e mental, além das emergentes ciências humanas, sociais, com destaque para a psicologia. Esse movimento tinha como pressuposto a intervenção sobre o indivíduo, seu corpo, sua mente, e não apenas sobre o ambiente físico, para com isso normalizá-lo para o mundo produtivo (COELHO; ALMEIDA FILHO, 1999). O homem passou a ser entendido mais como uma parte da engrenagem da nascente indústria:

[...] o homem, tal como a máquina, poderia ser consertado e programado. Listar as possibilidades normais de rendimento do homem, suas capacidades, bem como os parâmetros do funcionamento social normal passou a ser tarefa da psiquiatria e sociologia (COELHO; ALMEIDA FILHO, 1999, p. 22).

De acordo com Foucault (1999), na obra História da Sexualidade, o poder sobre a vida, o biopoder exercido por diferentes campos de conhecimento e instituições sociais, a partir do século XVII desenvolveu-se tomando duas ideias centrais, a primeira entendendo o corpo como máquina, aquele adestrado, desenvolvido, útil e dócil, integrado a sistemas de controle orientados por procedimentos de poder disciplinador, tanto físico quanto político. Outra forma de biopoder ocorreria por meio da organização/ordenação planejada e de controle dos elementos vitais, como nascimento, expectativa de vida, nível de saúde, efetivando a biopolítica sobre a população. 
As disciplinas do corpo e as regulações da população constituem os dois polos em torno dos quais se desenvolveu a organização do poder sobre a vida. A instalação durante a época clássica, desta grande tecnologia de duas faces - anatômica e biológica, individualizante e especificamente, voltada para os desempenhos do corpo e encarando os processos de vida - caracteriza um poder cuja função mais elevada já não é mais matar, mas investir sobre a vida, de cima para baixo (FOUCAULT, 1999, p. 131).

Dessa forma, o debate sobre o normal e o patológico ganhou outros contornos, pois a medicina, principalmente a partir do século XIX passou a apoiar a análise de um funcionamento regular, normal, para detectar em que o indivíduo teria se desviado. A partir das reformas da instituição pedagógica e da instituição sanitária, o termo normal foi disseminado de forma mais popular, significando o estado da saúde orgânica e, no campo escolar, a evidência desse movimento é a nomenclatura atribuída à escola normal como aquela que ensinava a ensinar (CANGUILHEM, 2009).

Portanto, o processo de medicalização é resultado de uma maneira de conceber o processo saúde-doença, da forma como se realiza o diagnóstico de dado problema. A medicina veio, ao longo dos anos reforçando a medicalização dos diferentes problemas, sejam eles sociais ou educacionais, à medida que se amparou na lógica da disciplinarização dos hábitos e costumes.

\subsection{O processo de medicalização na escola}

O processo de buscar causas físicas ou de saúde para os problemas de aprendizagem pode ser denominado como medicalização dos problemas escolares. De acordo com Collares e Moysés (1994), medicalizar é transformar problemas que originalmente não possuem uma causa médica, biológica, em problemas médicos a serem tratados exclusivamente pela saúde.

$\mathrm{O}$ processo de medicalização dos problemas de aprendizagem emerge como consequência do movimento no campo da saúde que tomou como elementos basilares e hegemônicos a explicação de que todos os problemas são de origem biológica e/ou médica.

Collares e Moysés (1992), ao analisarem o significado para a educação do que se convencionou denominar distúrbios de aprendizagem problematizam a justificativa teórica da divulgação desses conceitos no espaço escolar. Para as autoras, as definições: "distúrbios", "disfunção", “doença”, tendo por manifestações a desatenção, hiperatividade, confusão, agressividade, déficit de concentração carecem de critérios que objetivamente definam se tais manifestações são decorrentes de alterações neurofisiológicas. Nesse sentido é comum que os diagnósticos de qualquer inadaptação do aluno na escola fiquem no campo da presunção, ou 
seja, os conceitos amplamente divulgados ficam "[...] vagos, imprecisos, que se baseiam em exclusões e em referências a sinônimos e/ou outros conceitos, que por sua vez, também carecem de precisão" (COLLARES; MOYSÉS, 1992, p. 38).

O campo da educação, desde o século XX, se rendeu aos discursos técnicos, na cientificização sobre a criança resultando na construção de um discurso pedagógico normalizador, juntamente com a psicologização cujo desdobramento tem sido o encaminhamento para psicologia, fonoaudiologia, psicopedagogia, psiquiatria, entre outras, que fortalecem cada vez mais o discurso em que o fenômeno da psicologização da escola cede lugar a psiquiatrização do discurso escolar (GUARIDO, 2007).

Tradicionalmente, a psiquiatria julgou o desenvolvimento das crianças igual a psiquiatria dos adultos e assim, pelo campo orgânico, estas diferenças praticamente inexistem já que toda a dimensão histórica se faz ausente devido a aplicação do paradigma da psiquiatria biológica que adota a institucionalização da loucura, o poder centrado no discurso médico sobre a doença e, aos sujeitos resulta o fracasso dos tratamentos e a segregação dos indivíduos com as propostas terapêuticas disciplinadoras especialmente, no caso das crianças a medicalização e os diagnósticos descritivos, onde são amplamente utilizados. Não é incomum observar que o nome do aluno seja substituído por sua classificação diagnóstica destacando assim o lugar que ele ocupa (GUARIDO, 2007).

Muitas vezes, os profissionais da educação se rendem ao discurso das especialidades, assim, a pedagogia desresponsabiliza a escola e culpa as crianças e suas famílias pelo fracasso escolar. A transferência da culpa dos problemas para o indivíduo é difundida na sociedade por diferentes meios, seja pela mídia, produções teóricas, teorias pedagógicas, as quais divulgam um raciocínio simplista que acaba naturalizando o sofrimento da criança e seus problemas de aprendizagem como algo exclusivamente individual e biológico; professores e coordenadores, ao observar certos comportamentos acabam encaminhando precocemente para avaliação psiquiátrica, neurológica e/ou psicológica (GUARIDO, 2007; COLLARES, MOYSÉS, 1989).

Guarido (2007) afirma que ao fazer a crítica ao processo de medicalização do comportamento infantil, não está se rejeitando todo e qualquer uso de psicofármacos ou terapias, pois tais medicações são importantes em alguns casos e geram efeitos positivos. Contudo, é necessário revelar os efeitos de um movimento que banaliza a existência de problemas, ao diagnosticar todos os comportamentos como transtornos, além de naturalizar os sofrimentos e individualizar os problemas.

O conceito de "normal" não é estático ou rígido, mas dinâmico; se relaciona ao contexto em que está sendo utilizado. Normal refere-se etiologicamente ao conceito norma, 
uma regra, aquilo que serve para retificar, padronizar. "Normar, normalizar é impor uma exigência a uma existência, a um dado, cuja variedade e disparidade se apresentam, em relação à exigência, como um indeterminado hostil, mais ainda que estranho" (CANGUILHEM, 2009, p. 109).

A linha divisória entre o normal e o patológico não é precisa para diversos casos ou indivíduos considerados simultaneamente, mas pode ser utilizada para um único e mesmo indivíduo. "Aquilo que é normal, apesar de ser normativo em determinadas condições, pode se tornar patológico em outra situação, se permanecer inalterado" (CANGUILHEM, 2009, p. 71).

Ainda de acordo com Canguilhem (2009), não existe um caso/indivíduo, um fato que seja normal ou patológico em si; as diferenças expressas pelas denominadas anomalias, distúrbios, mutações ou diferenças não são em si mesmas patológicas, elas expressam outras normas de vida. Portanto, as normas pactuadas socialmente acabam determinando o julgamento do que seja patológico, em outras palavras, a normalidade advém da normatividade. "O patológico não é a ausência de norma biológica, é uma norma diferente, mas comparativamente repelida pela vida" (CANGUILHEM, 2009, p. 56).

Assim, segundo Collares e Moysés (2011), não é raro que crianças que apresentem um baixo rendimento escolar sejam encaminhadas para o setor de saúde já com um “diagnóstico", sendo na maioria das vezes, os motivos dos encaminhamentos de ordem biológica, desde desnutrição até distúrbios neurológicos. É possível perceber que a escola, por diversas razões, acaba reforçando o discurso medicalizante dos problemas relacionados ao processo ensinoaprendizagem e, muitas vezes reage mal a encaminhamentos que não retornam com prescrições para tratamentos medicamentosos/medicalizantes.

As autoras, ao pesquisarem os discursos que buscam explicar o fracasso escolar no cotidiano escolar evidenciam diferentes justificativas:

As crianças não aprendem porque são pobres, porque são negras, ou por serem nordestinas, ou provenientes de zona rural; são imaturas, são preguiçosas; não aprendem porque seus pais são analfabetos, são alcoólatras, as mães trabalham fora, não ensinam os filhos [...] (COLLARES; MOYSÉS, 2011, p. 196).

É possível perceber que os discursos atribuem tendencialmente para o aluno ou sua história de vida, as razões das dificuldades de aprendizagem, não refletindo sobre os limites da organização pedagógica do ensino, das políticas educacionais, da organização da escola ou 
da formação docente ou das condições sociais que determinam suas condições de vivenciar, no ambiente escolar e fora dele experiências que alarguem suas condições de aprendizagem.

Ao permitir que a lógica medicalizadora adentre ao espaço escolar reforça-se outro movimento que tem tomado cada vez mais corpo no debate escolar que é o uso de medicamentos como alternativa para superar o não aprender. Atualmente tem se tornado comum a ideia de que crianças e adolescentes, ao apresentarem alguma inadaptação ao contexto escolar devam utilizar algum remédio como forma para conter e promover as condições de aprendizagem.

Neste panorama, o Transtorno Déficit de Atenção e Hiperatividade (TDAH) tem sido descrito como um dos diagnósticos que mais sustenta o processo atual de medicalização da vida, devido ao crescente consumo de metilfenidato (ORTEGA et al. 2010; BRASIL, 2012).

De acordo com Moysés (2012, p. 1) existe uma contradição em nossa sociedade, em relação ao consumo de medicamentos pois: "Há campanhas contra o uso de anfetaminas por adultos, mas utilizam um medicamento com o mesmo efeito em crianças". Adverte quanto ao abuso da prescrição do metilfenidato para crianças e adolescentes mais agitados, ou seja, questiona a avalanche de diagnóstico de crianças com TDAH e em decorrência seu tratamento medicamentoso. Aponta que no Brasil o uso do metilfenidato, mais especificamente a Ritalina ${ }^{\circledR}$ aumentou $775 \%$ em dez anos, fazendo do país o segundo maior consumidor do medicamento.

Há produções de diferentes autores que advertem ainda que essa "epidemia" de diagnósticos produz, na mesma escala, uma "epidemia" de tratamentos, muitos dos quais altamente prejudiciais à saúde, especialmente nos casos em que não seriam, de fato, necessários. Tal situação tornou-se altamente vantajosa para a indústria farmacêutica, que nos últimos anos tem ampliado seu poder financeiro no campo da saúde (CALIMAN, 2006; CAPONI, 2009; DECOTELLI; BOHER; BICALHO, 2013; GUARIDO, 2007; GOMES; HENNING, 2015; MOYSÉS; COLLARES, 2013; MOYSÉS, 2012).

Patto (2015), ao buscar as origens da explicação da produção do fracasso escolar no Brasil identificou várias explicações que emergiram em diferentes contextos históricos e articuladas às demandas político sociais específicas. O fracasso escolar foi entendido, ao longo do tempo, por diferentes teorias, as quais o definiram como: a) resultado de distúrbios ou desvios psíquicos, compreensão fortemente influenciada pela medicina; b) carência cultural; c) resultado dos fatores intraescolares e d) resultado das condições de vida dos alunos. A autora destaca que essas concepções colonizaram o ideal educacional e de pesquisa no campo da educação brasileira e, num movimento de rupturas e continuidades muitas das 
explicações do fracasso escolar permanecem no cenário escolar buscando justificar as causas do não aprender.

Segundo Angelucci, Kalmus, Paparelli e Patto (2004), o fracasso escolar é tema de estudos desde a origem da pesquisa no campo educacional no Brasil nos anos de 1940, tendo naquele momento, o primado da área da psicologia, a qual sobre a influência do movimento da Escola Nova passou a dedicar-se ao estudo do processo ensino-aprendizagem e da criação de instrumentos de avaliação psicológica e pedagógica do aluno. Cabe destacar que para a Escola nova, o problema da não aprendizagem residia nos métodos de ensino e não no aluno (PATTO, 2015).

Angelucci et al. (2004), ao apresentarem o estado da arte da pesquisa sobre o fracasso escolar na Universidade de São Paulo no período de 1991-2002 destacam que nos últimos anos houve a presença significativa de estudos que compreendem o fracasso escolar como fenômeno centralmente individual, sendo sistematizados em três categorias de análise. A primeira destaca a vertente que parte do princípio de que o aluno é o responsável por seu fracasso escolar, por possíveis prejuízos cognitivos, psicomotores ou neurológicos. As duas outras categorias indicam que o fracasso escolar ora é responsabilidade do aluno ora do professor e “[...] propõem soluções predominantemente técnicas, de base teórica comportamental ou cognitivista, para eliminar o fracasso" (ANGELUCCI et al. 2004, p. 60).

O fracasso escolar vem sendo problematizado por alguns estudos no campo da educação, havendo pesquisas que evidenciam em números, a não aprendizagem dos alunos no sistema escolar brasileiro (PATTO, 2015; FORGIARINI; SILVA, 2016; MOYSÉS, COLLARES, 2013).

O termo fracasso escolar tem sido utilizado comumente no contexto educacional como um conceito amplo ou como se por si só exprimisse o seu real significado, contudo carece problematização. Fracasso escolar tem sido entendido como: “[...] baixo rendimento do aluno, aquisição insuficiente dos conhecimentos e habilidades, defasagem na relação idade-série, reprovação, repetência, interrupção escolar sem a obtenção de um certificado [...] (ZAGO, 2011, p. 58).

A escola encontra-se permeada por discursos que têm enfocado o aspecto biológico do desenvolvimento cognitivo dos alunos, os quais reforçam que os problemas de aprendizagem precisam ser tratados pelo campo da saúde e com medicamentos. Acredita-se que o uso do remédio é o único responsável pela variação do comportamento e que este não tem, ou tem pouca relação com o interior do cotidiano escolar. A educação encontra-se, mais uma vez atravessada pelo discurso especialista e só ganhará liberdade quando se apoderar do ato 
educativo proporcionando, assim acesso as crianças, independentemente de suas denominações ou rotulações diagnósticas (GUARIDO, 2007).

O discurso ideológico de que a escola é para todos, mas nem todos podem aproveitar essa oportunidade em decorrência de problemas individuais, ou seja, nem todas as crianças reuniriam as condições para aprender os conteúdos escolares, exalta o uso da medicalização como algo natural para a solução dos problemas individuais de cada criança submetendo-as a um processo de empobrecimento material e espiritual, desresponsabilizando a escola de qualquer culpa existente nesse processo (MEIRA, 2012).

Meira (2012) destaca que é marcante no cotidiano escolar, o discurso que vincula, de forma unicausal, problemas neurológicos a não aprendizagem e ao não aprender e não se comportar promovendo assim encaminhamentos de grandes contingentes de alunos com queixas escolares aos serviços de saúde.

Decotelli; Boher e Bicalho (2013), em artigo que buscou refletir sobre o processo de medicalização das dificuldades de aprendizagem, indicam que para que a medicalização se justificasse no cotidiano da escola criou-se patologias para definir diferenças no processo de aprendizagem; para categorizar a desobediência às normas ou para definir o que seria normal e esperado do comportamento dos alunos. "Dessa forma, é possível a captura do viver pelo discurso biomédico. As patologias são tornadas visíveis para que se invisibilizem as formas consideradas desviantes de vida no existir atual” (p. 451).

Em pesquisa realizada por Cord et al. (2015), junto a profissionais que atuam como articuladores entre Unidades Básicas de Saúde e escolas, na implementação do Programa Saúde na Escola (PSE) analisou-se quais as significações dos profissionais acerca das dificuldades de aprendizagem escolar e a relação dessas significações com os encaminhamentos via PSE. O estudo indicou duas questões centrais, a primeira compreensão era de que as dificuldades de aprendizagem, geradoras do fracasso escolar, decorriam da família pobre e/ou desestruturada; a segunda entende que as dificuldades de aprendizagem são decorrentes de problemas do aluno e como resultado da escola e as políticas públicas como co-produtoras das dificuldades de aprendizagem.

Ainda de acordo com Cord et al. (2015), o PSE teve papel como um agente que pode contribuir para o diagnóstico e medicalização das dificuldades de aprendizagem. Os profissionais envolvidos no PSE acreditam que a parceria da escola com a saúde é fundamental para solucionar as dificuldades de aprendizagem e, por isso realizaram encaminhamentos para a maioria dos alunos para psicólogo, médico e assistente social e em 
menor número para uma equipe multidisciplinar constituída por neuropediatra, pediatra, psicólogo, fonoaudiólogo, profissional da educação física, pedagogo e assistente social.

Torna-se importante denunciar que é marcante a crença de que a resolução das dificuldades de aprendizagem expressas no processo educativo por crianças e adolescentes é impossível sem recorrer à medicalização e, assim, o discurso biomédico insere-se cada vez mais no cotidiano escolar através de uma prática voltada ao diagnóstico e à medicalização da diversidade de modos de ser e de aprender, dando origem a um processo histórico de homogeneização dos sujeitos e subjetividades excluindo, assim, os que não se enquadram nos padrões estabelecidos. É de extrema urgência, que educadores e profissionais da saúde sejam instrumentalizados para a compreensão das dificuldades de aprendizagem a partir de uma perspectiva ética e política e, para isso caberia um posicionamento da psicologia quanto aos objetivos da educação escolar e ao papel social da escola para uma reflexão do que realmente é a queixa escolar (CORD et al., 2015).

\section{Conclusão}

O processo de medicalização está assentado na ideia de que os problemas, das mais variadas ordens, são resultados exclusivamente de fatores internos, biológicos ou psicológicos, do indivíduo. Os pressupostos da medicalização tem se espraiado na atualidade para vários setores sociais e buscado explicar situações/problemas complexos dos sujeitos, contudo, o que tem se evidenciado é a culpabilização do indivíduo pelas causas dos diferentes problemas.

A medicalização parte do pressuposto de que há um padrão do que seria normal a ser considerado no organismo ou no comportamento do indivíduo e, consequentemente o que foge do esperado passa a ser entendido como patológico. Essa lógica no ambiente escolar tem gerado um fenômeno que carece ser problematizado, pois ao considerar que os problemas dos alunos são de ordem biológica isentam-se os fatores intraescolares relacionados, principalmente, aos encaminhamentos metodológicos do processo ensino-aprendizagem.

A normalidade está a um passo de ser diagnosticada como patológica e os motivos que levariam a tal situação facilmente podem ser listados pela: sobrecarga de trabalho, problemas familiares, execução de tarefas as quais os sujeitos não possuem nenhuma afinidade, período de sono insuficiente, ingestão de alimentos inadequados; encaminhamentos didáticopedagógicos frágeis em promover a aprendizagem, esses e outros motivos podem reforçar o desconforto, desinteresse e inquietude dos alunos em sala de aula. Há que se pensar nos métodos e estratégias utilizadas pelos professores para motivar o aluno para a aprendizagem, 
dentre tantas outras causas que rotineiramente afetam a capacidade individual de aprendizagem, bem como, superar os diagnósticos precoces de TDAH ou outros distúrbios.

A instituição escolar precisa assumir que o não aprender e as dificuldades de aprendizagem dos alunos, em grande medida, podem ser decorrentes de encaminhamentos escolares internos, além disso, cabe aos profissionais da educação trabalhar para a solução dos mesmos sem recorrer de imediato ao campo da saúde, para isso é fundamental lançar mão de estratégias para promover esses indivíduos e não mais culpabilizá-los por suas dificuldades. Os encaminhamentos de escolares para os serviços de saúde precisam ser realizados somente para aqueles que não apresentaram evolução após inúmeras e variadas abordagens didáticopedagógicas para superação de dificuldades, portanto, para aqueles escolares que realmente possuem problemas de ordem biológica. Essa postura contribuiria para o não aumento do número de crianças medicalizadas por dificuldade de aprendizagem.

Diante de tal conduta, a escola estaria desempenhando o seu papel em educar os sujeitos e não de disciplinarizá-los para que se adaptem somente as regras e normas, cabe trabalhar com as características peculiares de cada indivíduo, não excluindo os sujeitos que se apresentam fora do padrão estabelecido como normal.

\section{Referências}

ANGELUCCI, C. B. et al. O estado da arte da pesquisa sobre o fracasso escolar (1991-2002): um estudo introdutório. Educação e Pesquisa, v. 30, n.1, p. 51-72. Jan./abr. 2004. ISSN 1678-4634. Disponível em: http://www.scielo.br/pdf/ep/v30n1/a04v30n1.pdf. Aceso em: 04 abr. 2017.

BRASIL. Agência Nacional de Vigilância Sanitária. Boletim de Farmacoepidemiologia. Prescrição e consumo de metilfenidato no Brasil: identificando riscos para o monitoramento e controle sanitário, ano 2, n. 2, jul./ dez. 2012a. Disponível em:

http://www.anvisa.gov.br/sngpc/boletins/2012/boletim_sngpc_2_2012_corrigido_2.pdf. Acesso em: 05 jan. 2017.

CALIMAN, L. V. A Biologia moral da atenção: a construção do sujeito desatento. 2006. 170 f. Dissertação (Doutorado em Saúde Coletiva) - Instituto de Medicina Social, Universidade do Estado do Rio de Janeiro, Rio de Janeiro. 2006.

CANGUILHEM, G. O normal e o patológico. 6. ed. rev. Rio de Janeiro: Forense Universitária, 2009. 154 p.

CAPONI, S. Biopolítica e medicalização dos anormais. Physis: Revista de Saúde Coletiva, v. 19, n. 2, p.529-549, 2009. ISSN 1809-4481. Disponível em: http://www.scielo.br/pdf/physis/v19n2/v19n2a16.pdf. Acesso em: 13 out. 2017. 
COELHO, M. T. A.; ALMEIDA FILHO, N. Normal-Patológico, saúde-doença: revisitando Canguilhem. Phisis: Revista de Saúde Coletiva, v. 9, n.1, p. 13-36, june. 1999. ISSN 01037331. Disponível em: http://www.scielo.br/pdf/physis/v9n1/02.pdf. Acesso em: 20 jul. 2017.

COLLARES, C. A. L.; MOYSÉS, M. A. A. Preconceitos no cotidiano escolar: ensino e medicalização. Campinas: Cortez, 2011. 264 p.

A Transformação do Espaço Pedagógico em Espaço Clínico: Patologização da Educação. Série Ideias. FDE, n. 23. p. 25-31. 1994. Disponível em: http://www.crmariocovas.sp.gov.br/pdf/ideias_23_p025-031_c.pdf. Acesso em: 01 ago. 2017.

História não contadas dos distúrbios de aprendizagem. Cadernos Cedes, Campinas: Papirus, n. 28, p. 31-48. 1992.

. Educação, Saúde e formação da cidadania na escola. Educação e Sociedade. São Paulo. n. 32, p. 73-87, abr., 1989.

CORD, D. et al. As significações Profissionais que Atuam no Programa Saúde na Escola (PSE) acerca das dificuldades de aprendizagem: patologização e medicalização do fracasso escolar. Psicologia: Ciência e Profissão, v. 35, n.1, p. 40-53, mar. 2015. ISSN 1414-9893. Disponível em: http://www.redalyc.org/articulo.oa?id=282038428004. Acesso em: 10 out. 2017.

CORDEIRO et al. Revisão sistemática: Uma revisão narrativa. Revista do Colégio Brasileiro de Cirurgiões, Vol. 34 - Nº 6, p. 428-431, nov/dec. 2007. ISSN 1809-4546. Disponível em: http://www.scielo.br/pdf/rcbc/v34n6/11.pdf. Acesso em: 31 Mar. 2017

DECOTELLI, K. M.; BOHER, L. C. T.; BICALHO, P. P. G. A droga da obediência: medicalização, infância e biopoder - notas sobre clínica e política. Psicologia: Ciência e Profissão. v. 22, n. 2, 2013. ISSN 1414-9893. Disponível em: http://www.scielo.br/pdf/pcp/v33n2/v33n2a14.pdf. Acesso em: 20 jul. 2017.

FORGIARINI, S. A. B.; SILVA, J. C. Fracasso escolar no contexto da escola pública: entre mitos e realidades. Portal dia a dia da educação, Paraná, 2016. Disponível em: http://www.diaadiaeducacao.pr.gov.br/portals/pde/arquivos/369-4.pdf. Acesso em: 09 out. 2016

FOUCAULT, M. História da Sexualidade I: a vontade de saber. Rio de Janeiro: edições Graal, 1999. 151 p. O nascimento da Clínica. Rio de Janeiro: editora Forense, 1977. 241 p.

GOMES, R. K.; HENNING, F. A medicalização da infância e o crescimento do uso de psicofármacos por crianças no Brasil. Revista de Extensão e Iniciação Científica Unisociesc. Curitiba, v. 2, n. 1, p. 13-30, 2015. Disponível em: http://www.sociesc.org.br/reis/index.php/reis/article/view/62/117. Acesso em: 3 jan. 2017.

GUARIDO, R. A medicalização do sofrimento psíquico: considerações sobre o discurso psiquiátrico e seus efeitos na Educação. Educação e Pesquisa, v.33, n.1, p. 151-161, apr. 
2007. ISSN 1517-9702. Disponível em: http://www.scielo.br/pdf/ep/v33n1/a10v33n1.pdf. Acesso em: 12 out. 2017.

MEIRA, M. E. M. Para uma crítica da medicalização na educação. Psicologia Escolar e Educacional, v. 16, n. 1, p. 135-142. June. 2012. ISSN 2175-3539. Disponível em: http://www.redalyc.org/html/2823/282323570014/. Acesso em: 20 out. 2016.

MOYSÉS, M. A. A. Portal da Unicamp, Página dupla. Disponível em: http://www.unicamp.br/unicamp/sites/default/files/clipping/revista_metropole_pag_10_e_11. pdf. Acesso em: 20 out. 2016.

MOYSÉS, M. A.; COLLARES, C. A. L. Controle e medicalização da infância. Desidades, ano 1, n. 1, p. 11-21, dez. 2013. ISSN 2318 - 9282. Disponível em:

http://desidades.ufrj.br/wp-content/uploads/2013/12/DESidades-1-port.pdf. Acesso em: 20 mai. 2017.

ORTEGA, F. et al. Ritalina no Brasil: produção, discurso e práticas. Interface - Comunicação, Saúde, Educação, v. 14, n. 34, p. 499-510, jul./set. 2010. ISSN 1414-3283. Disponível em: http://www.scielo.br/pdf/icse/v14n34/aop1510.pdf. Acesso em: 10 out. 2017.

PATTO, M. H. S. A produção do Fracasso escolar: histórias de submissão e rebeldia. 4 ed. revisada e aumentada. São Paulo: intermeios, 2015. 454 p.

SINGER, P. Prevenir e curar: o controle social através dos serviços de saúde. Rio de Janeiro: Forense Universitária, 1978. 166 p.

ZAGO, N. Fracasso e sucesso escolar no contexto das relações família e escola: questionamentos e tendências em sociologia da educação. Revista Luso-Brasileira, ano 2 n. 3 , p. 57-83, 2011. Disponível em: https://www.maxwell.vrac.pucrio.br/17155/17155.PDFXXvmi=. Acesso em: 20 out. 2017. 